Now, the earliest ray-florets would naturally be bright yellow, like the tubular blossoms of the central disk from which they sprang. And to this day the ray-florets of the simplest corymbiferous types, such as the corn-marigold (Chrysanthemum segetum), the sun-flower (Helianthus annuus), and the ragwort (Senecio jacobca), are yellow, like the central flowers. In the camomile, however, the ox-eye daisy, and the may-weed (Anthemis cotula, Chrysanthemum leucanthemum, \&c.), the rays have become white; and this, I think, fairly establishes the fact that white is a higher development of colour than yellow; for the change must surely have been made in order to attract special insects. In the true daisy, again (Bellis perennis), the white rays become tipped with pink, which sometimes rises almost to rose-colour (Fig. I6); and this stage is exactly analogous to that of apple-blossom, which similarly halts on the way from white petals to red. In our own asters (A. tripolium, \&c.) and the Michaelmas daisies of America, we get a further advance to purple, lilac, and mauve, while both in these and in the chrysanthemums, true shades of blue not infrequently appear. The Cinerarias of our gardeners are similar forms of highly-developed groundsels from the Mediterranean and the Canary Islands.

Tubular flowers with an irregular corolla are obviously higher in their mode of adaptation to insect visits than tubular flowers of the ordinary symmetrical type. Amongst them, the first place must be assigned to the Labiates. Not only are they deeply tubular, but they are very bilateral and irregular indeed, displaying more modification of form than almost any other flowers except the orchids. They mostly secrete abundant honey, and often possess highly aromatic perfumes. Almost all of them are purple or blue. Among the best known English species are thyme, mint, marjoram, sage (Fig. I 7), and basil, which it need hardly be said are great favourites with bees. Ground-ivy (Nepeta glechoma) is bright blue; catmint (Nepeta cataria), pale blue; Prunella, violet-purple; and common bugle (Ajuga reptans), blue or flesh colour. Many of the others are purple or purplish. It must be added that in this family the flowers are very liable to vary within the limit of the same species; and red, white, or purple specimens are not uncommon in many of the normally blue kinds.

The Scrophularinee, and other allied irregular tubular families are mostly spotted, and so belong to a later stage of our inquiry ; but even amongst this group, the Veronica genus has almost always pure blue flowers; foxglove (Digitalis purpurea) is purple; and many of the Broomrapes (Orobanchacee) are more or less bluish. Blue and lilac also appear abundantly in spots or stripes in many species of Linaria, in Euphrasia, and in other genera.

We have given so much consideration to the Dicotyledons that the relatively simple and homogeneous Monocotyledons need not detain us long. Their coloration is as a whole both less complicated and less instructive.

The Alismacea answer very closely to the Ranunculacea, as being in all probability the earliest surviving type of entomophilous Monocotyledons. Their arrangement is of course trinary, but they have similarly separate carpels, often numerous, surrounded by one, two, three, or many rows of stamens, and then by one row of three petals and one row of three sepals. All our English species, however, are white or rosy, instead of yellow. As they are marsh plants, they seem to have reached or passed the stage of Ranunculus aquatilis. One species, Alisma plantago, the water-plantain, however, still retains a yellow claw to the petals, though the limb is white or pale pink. So also does Damasonium stellatum. These two interesting plants present a remarkable analogy to the water-crowfoot.

Among monocotyledonous families with a united ovary the Liliacee are probably the most primitive. Their simplest type in England is Gagea lutea (Fig. 18), a yellow lily looking extremely like a bunch of Ranunculus Ficara. In Lloydia serotina, a closely allied but more developed form, the petals are white, with a yellow base, and three reddish lines. The wild tulip is likewise yellow. Allium ursinum, a somewhat higher type, is pure white. The fritillary (Fritillaria Meleagris, Fig. I9), a large, handsome, bell-shaped flower, with separate petals converging into a campanulate form, and with a nectariferous cavity at their base, is purple or red, checquered with lurid marks; but it often reverts to white, or even to a faint yellow. In Scilla, however, including our common wild hyacinth ( $S$. nutans), the deep tubular flowers, composed of perianth pieces with long claws, are usually blue, rarely pink or white; while in Hyacinthus and Muscari, which have a united bell-shaped or globular blossom, formed by the coalescence of the sepals and petals, dark-blue and ultramarine are the prevalent tones. Meadow saffron (Colchicum autumnale), which has also a united tube and very deep underground ovary, is a fine reddish purple: its stamens secrete honey.

The Iridec and Amaryllidece are more advanced than the lilies, in that they possess inferior ovaries-in other words, their perianth tube has coalesced with the walls of the inclosed carpels. In many cases, especially in the more highly-developed species, their flowers are red, blue, or purple. Trichonema Bulbocodium is purplish-blue, with a yellow centre. Our two native crocuses ( $C$. vermus and $C$. nudiflorus) are also purple. Sisyrinchium Bermudianum is a delicate blue. Gladiolus communis is brilliant crimson. Iris fatidissima is violet. Our own Amaryllids are white or primrose, but brilliant reds and purples, as well as highly-developed spotted types, are common amongst the cultivated exotics.

The Orchidacece stand at the head of the entomophilous Monocotyledons by virtue of their inferior ovary, their irregular flowers, and their extraordinary adaptations to insect fertilisation. Purples are the prevailing groundtones (Fig. 20); but in the commonness of variegation and of specialised lines or spots of colour, the Orchids answer closely to the Scrophularinece among Dicotyledons, and may therefore best be considered in a succeeding section.

GRANT ALLEN

( $T$ o be continued.)

\section{ASTRONOMICAL OBSERVATORIES 1}

$A M O N G$ the contributions of public and private munifi-

cence to the advance of knowledge, none are more worthy of praise than those which have been devoted to astronomy. Among all the sciences, this is the one which is most completely dependent upon such contributions, because it has the least immediate application to the welfare of the individual. Happily, it is also the science of which the results are best adapted to strike the mind, and it has thus kept a position in public estimation which it could hardly have gained if it had depended for success solely upon its application to the practical problems of life. That the means which have been devoted to its prosecution have not always been expended in a manner which we now see would have been the best, is to be expected from the very nature of the case. Indeed, a large portion of the labour spent in any kind of scientific research is, in a certain sense, wasted, because the very knowledge which shows us how we might have done better has been gained through a long series of fruitless trials. But it is due both to ourselves and the patrons of astronomy that as soon as any knowledge bearing upon the question of the past application of money to the advance of science is obtained, use should be made of it to point out the mistakes of the past and the lessons for the future. It is now patent to all who have made a wide study of the subject that large amounts have been either wasted or applied in ways not the most effective in the erection and r From the North American Review. 
outfit of astronomical observatories. Since Tycho Brahe built his great establishment at Uraniburg, astronomical research has been associated in the public mind with lofty observatories and great telescopes. Whenever a monarch has desired to associate his name with science, he has designed an observatory proportional to the magnitude of his ambition, fitted it out with instruments on a corresponding scale, and then rested in serene satisfaction. If we measure greatness by cubic yards, then Peter the Great and "Le Grand Monarque" were the founders of two of the greatest observatories ever built. That of St. Petersburg was completed in I725, the year of Peter's death, and was an edifice of two hundred and twenty-five feet front, with central towers one hundred and forty feet high. It had three tiers of galleries on the outside for observation, and was supplied with nearly every instrument known to the astronomers of the time, without reference to the practicability of finding observers to use them. It was nearly destroyed by fire in 1747 , but was partially rebuilt, and now forms part of the building occupied by the Imperial Academy of Sciences. The Paris Observatory, built half a century earlier, still stands, its massive walls and arched ceilings reminding one rather of a fortress than of an astronomical institution.

Notwithstanding the magnificence of these structures, they have had little essential connection with the progress of astronomy. It is true that the work done at both establishments takes a prominent place in the history of science, but most of it could have been done equally well under wooden sheds erected for the protection of the instruments from the weather. In recent times, the St. Petersburg Observatory has been found so unsuitable for its purpose that no observation of real value can be made, and its existence has been nearly forgotten. The great building at Paris, though associated with a series of astronomical researches second to none in the world, has really served scarcely any other purpose than those of a physical laboratory, store-house, and offices. The more important observations have always been made in the surrounding garden, or in inexpensive wings or other structures erected for the purpose.

With these establishments it will be instructive to compare the Greenwich Observatory. The latter has never won the title of great. It was originally established on the most modest scale, for the special purpose of making such observations as would conduce to the determination of the longitude at sea. Although it has now entered upon its third century, no attempt has ever been made to reconstruct it on a grand scale. Whenever any part of it was found insufficient for its purpose, new rooms were built for the special object in view, and thus it has been growing from the beginning by a process as natural and simple as that of the growth of a tree. Even now, the money value of its structure is less than that of several other public observatories, although it eclipses them all in the results of its work. Haeckel lays it down as a general law of research that the amount of original investigation actually prosecuted by a scientific institution is inversely proportional to its magnitude. Although this may be regarded as a humorous exaggeration, it teaches what the history of science shows to be a valuable lesson.

A glance at the number and work of the astronomical observatories of the present time will show how great a waste of means has been suffered in their erection and management. The last volume of the American Ephemeris contains a list of nearly $\mathrm{I} 50$ observatories, supposed to be, or to have recently been, in a state of " astronomical activity." The number omitted because they have lain inactive it is impossible to estimate; but it is not unlikely that, in this country at least, they are as numerous as those retained. It is safe to say that nearly everything of considerable value which has been done by all these establishments could have been better done by two or three well-organised observatories in each of the principal civilised countries. Indeed, if we leave out of account local benefits, such as the distribution of time, the instruction of students, and the entertainment of the public, it will be found that nearly all the astronomical researches of really permanent value have been made at a very small number of these institutions. The most useful branch of astronomy has hitherto been that which, treating of the positions and motions of the heavenly bodies, is practically applied to the determination of geographical positions on land and at sea. The Greenwich Observatory has, during the past century, been so far the largest contributor in this direction as to give rise to the remark that, if this branch of astronomy were entirely lost, it could be reconstructed from the Greenwich observations alone. During the past twenty years the four observatories at Greenwich, Pulkowa, Paris, and Washington have been so far the largest contributors to what we may call geometrical astronomy that, in this particular direction, the work of the hundred others, in the northern hemisphere at least, can be regarded only as subsidiary.

This remark, it will be understood, applies only to that special branch of astronomy which treats of the positions and motions of the heavenly bodies. The other great branch of the science treats of the aspect and physical constitution of these bodies. It dates from the invention of the telescope, because, without this instrument and its accessories, no detailed study of the heavenly bodies is possible. The field open to the telescope has, during the last twenty years, been immensely widened by the introduction of the spectroscope, the ultimate results of which it is scarcely possible to appreciate. Photography has recently been introduced as an accessory to both instruments; but this is not so much an independent instrument of research as a means of recording the results of the spectroscope and telescope. To this branch of the science a great number of observatories, public and private, have duly contributed, but, as we shall presently see, the ratio of results to means is far less than it would have been had their work all been done on a well-organised system.

Nearly all great public observatories have hitherto been constructed for the purpose of pursuing the first branch of the science-that which concerns itself, so to speak, with the geometry of the heavens. This was naturally the practice before the spectroscope opened up so new and rich a field. Even now there is one sound reason for adhering to this practice,--namely, that physical investigations, however made, must be the work of individuals rather than of establishments. There is no need of a great and expensive institution for the prosecution of spectroscopic observations. The man of genius with imperfect instruments will outdo the man of routine in the greatest building, with the most perfect appliances that wealth can supply. The combination of qualities which insures success in such endeavours is so rare that it is never safe to count upon securing it. Hence, even now, a great observatory for the prosecution of physical research whould be a somewhat hazardous experiment, unless the work it was to do were well mapped out beforehand.

Considering the great mass of observatories devoted to geometrical astronomy, the first thing to strike the professional student of their work is their want of means for a really useful and long-continued activity; and this notwithstanding that their instrumental equipment may be all that could be required. The reason is that their founders have not sufficiently taken into account the fact that the support of astronomers and the publication of observations is necessary to the usefulness of such an establishment, and requires a much larger endowment than the mere outfit of the building. Let us take, for instance, that omnipresent and most useful instrument, the meridian circle. Four or five of these instruments, of moderate size, located in good climates, properly manned, under skilful superintendence, working in co-operation with each 
other, would do everything necessary for the department of research to which they are applicable, and a great deal more than is to be expected from all the meridian circles of the world, under the conditions in which they are actually placed. They could, within the first five years, make several independent determinations of the fundamental data of astronomy, including the positions and motions of several hundred of the brighter fixed stars. In five years more they could extend their activity so as to fix the position of every star in the heavens visible to the naked eye ; and, during the ten years following, could prepare such a catalogue of telescopic stars as there is no prospect of our seeing during the next half-century.

There are probably not less than twenty meridian circles in this country alone, most of them antiquated, it is true, yet, so far as average size and cost are concerned, amply sufficient for the work in question. How many there may be in other countries it is impossible to estimate, but probably fifty or upward, and the number is everywhere constantly increasing. Should we seek out what they are doing, we should probably find half of them rusting in idleness upon their pivots. With others some industrious professor or student would be found making, unaided, a series of observations to be left among the records of the establishment, or immured in the pages of the Astronomische Nachrichten, with small chance in either case of ever being used. We may be sure that the solitary observer will soon find something else to do, and leave the instrument once more in idleness. Others we should find employed in the occasional instruction of students, a costly instrument being used where a rough and cheap one, which the student could take to pieces and investigate at pleasure, would answer a far better purpose. Yet others we should find used in distributing time to the neighbouring cities or states, or regulating chronometers for the shipping of a port. I dare not guess how many we should find engaged in work really requiring an instrument of the finest class, and gaining results which are to contribute to the astronomy of the future, but in our own country there would hardly be more than three.

The general cause of this state of things lies upon the surface. It is as true in astronomy as in any other department of human affairs that the best results can be attained only by a careful adaptation of means to ends. Failures have arisen, not from the intervention of any active opposing agency, but because observatories have been founded without a clear conception of the object to be attained, and therefore without the best adaptation of means to ends. To build an observatory before knowing what it is going to do is much like designing a machineshop and putting in a large collection of improved tools and machinery before concluding what the shop is to make, and what are the conditions of the market open to its products. Some hints on the considerations which should come into play in the erection of any new observatory may not be out of place, as pointing out the remedy for the evils we have described.

Heretofore the practice has usually been first to decide upon the observatory, and to plan the building; next to provide instruments ; and lastly, to select an astronomer, and with his advice, to decide what direction the activities of the establishment should take. This order of proceeding should be reversed. The first thing to be done is to decide what the observatory shall be built to do. The future astronomer would, of course, have a controlling voice in this decision, and should, therefore, be selected in advance. One thing which it is especially important to decide is to which of the two great divisions of astronomical research attention shall principally be directed. If the prosecution of geometrical astronomy is kept in view, the conditions of advance in that department of the science must be kept in mind. The public is too apt to associate astronomy with looking through a telescope. That some of the greatest astronomers of modern times, such as Kepler, Newton, Hansen, Laplace and Leverrier scarcely ever looked through a telescope as astronomers, is not generally understood. For two thousand years astronomy has furnished the great geometers of the world with many of their profoundest problems, and thus has advanced hand in hand with mathematics. It borrows its fundamental data from observation, but the elaboration and development of its results taxes the powers of the mathematical investigator. The work of making the necessary observations is so much easier than that of developing the mathematical theories to which they give rise, that the latter is comparatively neglected alongside the former. It is lamentable to see what a collection of unused observations are found in the pages of scientific periodicals, to say nothing of those which have remained unpublished in the records of observatories. Under these circumstances it is not worth while to found any more observatories for the prosecution of geometrical astronomy, except under special conditions. Among these conditions we may enumerate the following :-

r. The institution should have such an endowment as to secure the continuous services of two or three observers, and to publish at least the results of their observations in a condensed form.

2. The instruments should be of the finest class, but not necessarily of large size. This is not a difficult condition to fulfil, since such instruments are not very costly. One reason for observing it is that it is only within the last few years that the highest perfection has been attained in the construction of instruments of measurement.

If these two conditions can be really fulfilled, it is very desirable to add a few more to the great number of meridian circles now in existence, for the simple reason that it is easy to exceed them in perfection. It is, however, to be remarked that a good climate is a scientific pre-requisite for the success of an observatory of any kind. The value of observations is "decidedly lessened by the breaks in their continuity due to the intervention of clouds. It is therefore extremely desirable that, so far as possible, new observatories should hereafter be erected under sunny skies.

If an observatory is to be devoted to physical research, a more modest outfit, both in the way of endowment and of instrumental means, may be sufficient to serve an excellent purpose. Instead of being a great co-operative work, requiring the continuous labour of several persons, physical research may be divided up into sections almost as small as we please, each of which may be worked by an individual astronomer with any instrument suited to the purpose in view. To the success of such an observatory a clear sky is even more necessary than to one engaged in measurement. Whether a great telescope will be necessary, will depend principally upon what is to be done. The consideration which is really of the first importance is the astronomer. The man who is really wanted will do more with the most inexpensive instruments than another one with the most costly ones. As already remarked, physical research is mainly the work of the individual, and what we want is to secure the services of the ablest man and then supply him with such means of research as are necessary to the problems he has in view. New questions are arising so frequently, and the field of physical research is now so wide, that it is impossible to lay down any general rules for a physical observatory, except that means should be furnished for supplying the investigator with any instrument he may want.

A third class of observatories are those intended for instruction in astronomy. The requirements in this direction are so different from those necessary to research that it is impossible to combine the highest efficiency in both directions with the use of the same instruments. The number of observatories especially designed for pure instruction are very few in number. The instruments 
necessary for the purpose are of the simplest kind indeed, so far as mere training is concerned, the engineer's level, transit, and theodolite can be made to serve most of the purposes of the astronomical student. What the latter really wants is that training of the eye and the mind which will enable him to understand the theories of instruments, the methods of eliminating the errors to which they are subject, and the mathematical principles involved in their application. In this, as in nearly every department of professional education, we may lay it down as a rule that the wants of a liberal and of a professional education are, so far as the foundation is concerned, identical. We are too prone to lead the student into the minute details of a subject without that previous training in first broad principles which, though it may not immediately tell on his progress as a student, will be felt throughout his life to whatever field of work he may devote himself. Such a transit instrument as Hipparchus might have made-a wooden level mounted on an axis and supplied with slits to serve the purpose of sightsproperly mounted in the meridian, could well be made to take the place of the transit instrument for purposes of instruction. Scarcely any higher skill than that of a cabinet-maker would be required in its construction. The object at which the student should then aim would be, with the aid of this instrument, to determine the error of his clock or watch within a few seconds. If he is really acquainted with the principles of the subject, and has his eyes properly trained, he will have no difficulty in soon learning to do this. SIMON NEWCOMB

\section{NOTES}

THE following details regarding the sad accident by which Prof. Balfour lost his life have been received since Prof. Foster's article was written. It appears (from a letter from Mr. C. D. Cunningham to the Times) that on the I 4 th ult. $\mathrm{Mr}$. Balfour crossed the Col du Géant, and on descending on the Italian side the idea first occurred to him of attempting the Aiguille Blanche de Peuteret, or, as it is sometimes called, the Aiguille de la Belle Etoile, a peak which is one of the buttresses of Mont Blanc, to the massif of which it is joined by an extremely steep snow arête. Mr. Cunningham's guide, Emile Rey, had previously attempted the peak, and was able to give Mr. Balfour many details as to the probable line of ascent. Having failed, however, to persuade $\mathrm{Mr}$. Cunningham and the guide Rey to accompany him, Mr. Balfour started from Courmayeur on Tuesday, the 18 th, with the guide Johann Petrus, for Aiguille, accompanied by a porter to carry blankets and wood as far as their sleeping-place on the rocks. It was thought, the ascent being new and difficult, he might be absent two nights, and return to Courmayeur on Thursday. As he did not reappear, it was thought he must have crossed to Chamounix, or gone down to the Chalets de Visaille for more provisions. On Friday Mr. Bertolini and Mr. Baker, at the hotel in Courmayeur, became seriously alarmed, and finding the party had not been heard of either at Chamounix or at the Chalets de Visaille, they sent out a search party, which, early on Sunday morning, on reaching the rocks between the Glacier de Brouillard and the Glacier de Fre ny, found the bodies of $\mathrm{Mr}$. Balfour and Petrus, both partly covered with snow, at the foot of the steep snow arête. As there was little fresh snow about the place, it was probably not an avalanche that caused their death. One may have slipped, and the other not bad sufficient strength to hold his compani n. The provisions at the sleeping-place having been untouched, the accident must have taken place on Wednesday, the I9th. But it is not certain whether they fell in descent or ascent. Means were taken on the $25^{\text {th }}$ to have the remains brought to the hotel.

THE three missions designated for observation of the Venus transit in Patagonia left on the 2oth ult. in the Messageries steamer from Bordeaux, for Buenos Ayres. The arrangement is as follows :-Rio Negro ( $\left.4 \mathrm{r}^{\circ} \mathrm{S}.\right)$, M. Perrotin, director of Nice Observatory, accompanied by Lieutenants Tessier and Delacroix, and M. Guénaire, photographer to the Observatory; Chubut $\left(43^{\circ}\right.$ S.), M. Hatt, hydrographic engineer, assisted by Lieut.

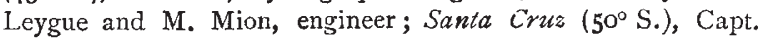
Fleuriais, assisted by Lieutenants Le Pord and de Royer de Saint Julien, and M. Lebrun, naturalist. Arrived at Monte Video, the first two missions will probably embark in the advice boat $\mathrm{La}$ Bourdonnais, the third in the advice boat Le Volage. In the course of observations, detachments from the Volage will try to ascend the Rio Santa-Cruz at least to the point reached by Darwin in the Beagle expedition. The Chili mission, composed of Lieut. de Bernardiére, assisted by Lieut. Barnaud and Ensign Favereau, embarked on the $15^{\text {th }}$ ult. in an English steamer going by the Straits of Magellan.

UNDER the name of a "North German Museum for Natural Science " Dr. G. Haller and Cie have opened at Putbus, on the island of Rügen, a storehouse of natural objects and aids to teaching, whence schools, museums, and private individuals may obtain specimens and collections, representing all the three kingdoms of nature. An institute for investigation of the Baltic forms part of the scheme, and a few students have been enrolled, we learn, for the current summer. Dr. Haller was formerly a privat-docent of zoology in Berne. With the aid of a well-known entomologist, collections of insects of all kinds (exotic included) are furnished ; also biological collections of caterpillars, larvæ, pupæ, parasites, \&c. It is intended, later on, to supply collections of the insect pests of agriculture. The utensils of entomologists and other apparatus are also provided. Of European manmals, birds, reptiles, amphibia, fishes, \&c., many specimens are kept, preserved in the usual way; also preparations for the study of embryology and comparative anatomy, and for varied microscopical work. A variety of live animals for aquaria and terraria are provided. The dry preparations of frogs and other animals obtained by a modification of Semper's method have received special commendation, also the series of embryos and parasites.

FrEE libraries do not increase in number so rapidly in England as in America, where they have now reached to 4000 . Yet a pamphlet or circular issued by the Bureau of Education must be of considerable interest to any who are engaged in starting or working libraries. It points out the disadvantages of the arrangements of existing library buildings, and gives a general plan by which they may be avoided. The chief American libraries consist of large halls open from floor to roof and surrounded by galleries five or six one over another like a theatre. The author of this paper ( $\mathrm{Mr}$ Poole of Chicago) objects to this general plan, on account of (I) the waste of this central space, or if this central space is used for reading, for its publicity and noisiness; (2) the difficulty of getting any uniform temperature over the whole of such a building, for while the lower floors are kept at a mild warmth the upper floors become so intensely hot that not even an attendant can work there, and the bindings perish from heat; (3) the wasteful expenditure of the physical strength and time of attendants in going upstairs and round from one part of the library to another; (4) the special convenience for catching fire where all communicate with one centre instead of being divided into fireproof compartments ; (5) the difficulty of enlarging such a circular building, as the principal American libraries already require enlarying; and (6) its great expense. In the plan which Mr. Poole suggests ten rooms surround a square space equal to only two of the rooms. Each room should be about 16 feet high, thus easily warmed uniformly. Books should be classified, and in a few cases duplicate copies kept so that a student should find all the books on the subject he wanted 